\title{
Can Star Systems be Explored?
}

\section{The Physics of Stitr Probes}

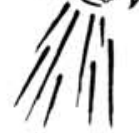

\section{Lawrence B. Crowell}

Alpha Institute of Advanced Studies, USA 


\section{Published by}

World Scientific Publishing Co. Pte. Ltd.

5 Toh Tuck Link, Singapore 596224

USA office: 27 Warren Street, Suite 401-402, Hackensack, NJ 07601

UK office: 57 Shelton Street, Covent Garden, London WC2H 9HE

\section{British Library Cataloguing-in-Publication Data}

A catalogue record for this book is available from the British Library.

\section{CAN STAR SYSTEMS BE EXPLORED? The Physics of Star Probes}

Copyright (C) 2007 by World Scientific Publishing Co. Pte. Ltd.

All rights reserved. This book, or parts thereof, may not be reproduced in any form or by any means, electronic or mechanical, including photocopying, recording or any information storage and retrieval system now known or to be invented, without written permission from the Publisher.

For photocopying of material in this volume, please pay a copying fee through the Copyright Clearance Center, Inc., 222 Rosewood Drive, Danvers, MA 01923, USA. In this case permission to photocopy is not required from the publisher.

ISBN-13 978-981-270-617-1

ISBN-10 981-270-617-8

ISBN-13 978-981-270-618-8 (pbk)

ISBN-10 981-270-618-6 (pbk)

Printed in Singapore. 
To Junko

ฐี ฮี 巳

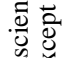

을

3

.

응

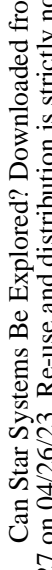

인

กิ

मे

ลุ 
This page intentionally left blank 


\section{Preface}

Many students are motivated by applications of physical theory instead of presentations of pure theory. Many students gain an interest in relativity early on from exposure to science fiction or from speculations on space travel. The depiction of futuristic space flight and exotic methods of spaceflight are often a catalyst for young people's interest in physics. This is the spirit in which this book was written. The intention here is to present Newton's mechanics, relativity and astrophysics with the question of whether it is possible to send a probe to another star. There have been some presentations on this prospect, such as the Daedalus project and Robert Forward's Starwisp. The prospect is tantalizing, and something which might take fruition in the future. In this light, the prospect of interstellar probes is discussed in the light of known physics. The reader is given the option to determine whether this is at all possible.

The current age presents us with some apparent limits on scientific knowledge and technological progress. This has been seen with the increased technical and financial problems which accompany the building of ever larger particle accelerators. It is also seen in the shortfall with the reality of manned spaceflight when compared to futuristic expectations of past decades. In spite of these apparent limits, scientific research has continued remarkably well. While manned space exploration appears blunted compared to early expectations, space science has made huge advances in astronomical and planetary research. Possibly, particle physics will develop new methods that circumvent current limitations, or even find new ways to convert matter to energy. Similar advances may occur with the exploration of space with probes. Probes have been sent to all of the planets in the solar system, except for Kuiper belt planets, and to a number of asteroids and comets. These probes have velocities limited by current technology, 
but with ion propulsion and VASMIR systems, it is certainly possible that larger craft will be sent into the solar system at much higher velocities. It is possible that technical limitations will be overcome and that in due time, probes might be sent to some of the nearby stars.

Physics has penetrated considerably into the public sphere. There has been a recent increase in popular interest in quantum mechanics and relativity. Popularizations of an increasingly sophisticated level have made their way into the general reading populace. Indeed, the distinction between texts, research books and popularizations has begun to fade in recent years. This book is meant to exist within the boundary between a text and a popularization. The general reader may find this an interesting route to reading about mechanics and relativity, and students may find this to be an entertaining supplemental source in addition to classroom lectures and texts. It might also stimulate some interest in the physics and engineering of space probes and in preliminary studies on the technical requirements for future star probes.

L. B. Crowell 


\section{Contents}

Preface vii

1. Exploration of Star Systems 1

2. Newtonian Mechanics 5

3. The Physics of Rocketry and Spaceflight 17

4. Power Systems for Spaceflight 31

5. Elements of Astrodynamics 43

6. Special Relativity 49

$\begin{array}{ll}\text { 7. The Relativistic Rocket } & 67\end{array}$

$\begin{array}{ll}\text { 8. The Photon Sail } & 79\end{array}$

9. Scientific and Technical Requirements 91

10. Electromagnetically Accelerated Nano-bots 101

11. Exotic Propulsion Methods 107

12. The Interstellar Neighborhood 119 
13. Will Humans go to the Stars?

14. Solar System Stability and the Likelihood of Earth-like Planets 141

15. Life on Earth and in the Universe

16. Appendix 183

Bibliography 185

Index 